\title{
POR LOS CAMINOS DIOCESANOS Acercamientos a la historia de la creación de la Diócesis de Cali ${ }^{*}$
}

\author{
Carolina Abadía Quintero ** \\ Antonio J. Echeverry Pérez
}

\begin{abstract}
Resumen
La historia de la Diócesis, es una historia desarrollada por laicos, con las ventajas $y$, seguras, desventajas que esto supone. No se pretende hacer una apología a la Iglesia, en su desarrollo regional, sino, mostrar con la mayor objetividad posible, las razones por las cuales surge ese proyecto de Diócesis y su consecuente proceso de separación de Popayán, a la cual había estado ligada indisolublemente por más de 350 años. Es una élite regional con aspiraciones de progreso político y económico, que se ven cristalizados con la creación del departamento, las que animan el desarrollo de la diócesis.
\end{abstract}

Palabras claves: Diócesis de Cali, Historia de la Iglesia.

\begin{abstract}
The history of the diocese, is a story by lay with the advantages and secure disadvantages that this entails. Not intended to make an apology to the Church, in their regional development, but show with the greatest possible objectivity, reasons why arises that diocese project and its consequent separation of Popayán, process to which had been tied inextricably for over 350 years. It is a regional elite with aspirations of political and economic progress are cristalizados with the creation of the Department, which encourage the development of the diocese.
\end{abstract}

Key words: Diocese of Cali, church history.

\footnotetext{
*articulo tipo 2, de reflexión según clasificación de Colciencias. Hace parte del proyecto de investigación "Diócesis de Cali. Un siglo de Historia Regional", avalado en convocatoria interna por la Vicerrectoría de investigaciones de la Universidad del Valle, 2009-2010.

** Docente y Coordinadora de la Cátedra en Historia, Universidad del Valle, sede Buga. Licenciada en Historia y Aspirante a Magister en Historia, Universidad del Valle. Asistente de Edición Revista Historia y Espacio, adscrita al Departamento de Historia, Universidad del Valle. Integrante de la Asociación Centro de Estudios Regionales REGIÓN, Departamento de Historia y del grupo Creencias, Religiones y Utopías, Departamento de Filosofía, Universidad del Valle. E-mail: cabaquin@gmail.com.

Doctor en Historia de América Latina, Universidad Pablo de Olavide. Magister en Historia Andina, y Licenciado en Historia de la Universidad del Valle. Docente e investigador, Universidad del Valle. Integrante de la Asociación Centro de Estudios Regionales REGIÓN, Departamento de Historia y del grupo Creencias, Religiones y Utopías, Departamento de Filosofía, Universidad del Valle. Es autor de los libros: "Teología de la Liberación en Colombia" y Franciscanismo. Un imaginario tras una utopía en la Nueva Granada del siglo XVI”. E-mail: aechever@univalle.edu.co
} 


\section{Cali y la erección de una diócesis}

Para el siglo XX, la Cali de 1910 contaba con 13.765 habitantes, que se encontraban ubicados en dos sectores de la ciudad, el "Vallano" y el "Empedrado", en los cuales existían 7 barrios: San Antonio, San Pedro, Santa Librada, Santa Rosa, San Nicolás, La Merced y el Calvario. En ellos se encontraban ubicados los conventos de San Francisco, La Merced, San Agustín, El de Misiones de San Joaquín y el de las Carmelitas descalzas.

Esta breve descripción de la ciudad muestra la fortaleza en materia religiosa, que será el gran aliciente para la erección de la diócesis. Una pequeña pero pujante Villa, que se liberaba de la clásica subordinación política y eclesiástica de Popayán. Pequeña en habitantes pero con importantes tradiciones religiosas, la villa caleña desde finales del siglo XIX, fue fortaleciéndose y creciendo, a medida que las dinámicas comerciales y empresariales fueron extendiéndose por la región.

Para inicios del siglo $X X$, un grupo importante de empresarios e integrantes de la encumbrada sociedad caleña, en pequeñas tertulias, empezaron a reflexionar sobre las formas de encauzar y proyectar de una mejor forma el gradual progreso que estaba presentando la región. Es así como en el primer decenio del nuevo siglo, traería consigo todo un cúmulo de propuestas y proyectos que conducirían el devenir histórico de la ciudad. El despertar de la presente época muestra no sólo una ciudad, sino un país que en general se reponía de la guerra, y pensaba en la necesidad de edificar proyectos de modernización política, social y cultural. Bajo este contexto es que finalmente se erige como Diócesis, la parroquia de Cali

Son variados los documentos que reposan en el Fondo Concejo del Archivo Histórico de Cali, que ilustran el panorama político y social en el que se iba gestando el proceso de creación del Departamento del Valle del Cauca. Proyecto que logra consolidarse gracias a la ley número 65 de 1909, la cual proveyó los insumos jurídicos para que las anteriores parcialidades de Buga y Cali, unieran esfuerzos, habitantes y rentas que les permitirían convertirse en unidad departamental. Es finalmente con el decreto 340 del 16 de abril de 1910, dictado por la presidencia de la República, que finalmente nace y se reconoce como departamento, al Valle del Cauca.

Cali, como capital reconocida de la nueva institución departamental, era además el escenario en el que se estaban presentando toda una serie de reformas que propendían por el mejoramiento de las condiciones sociales y económicas de sus pobladores. Mejoramiento de los servicios públicos (agua, energía y teléfono), pavimentación de las calles, construcción de acueducto, reglamentación sobre las basuras y la moral pública, consecución del proyecto del ferrocarril y reordenamiento del ornato de la ciudad, eran sólo algunas de las dinámicas que distintas instituciones y grupos locales lideraban en la ciudad. Paralelo a tales 
procesos se fueron creando la Sociedad de Mejoras Públicas, la Cámara de Comercio de Cali, y por supuesto la erección a Diócesis de la parroquia de Cali.

La capital del nuevo departamento poseía una importante tradición religiosa, que se ve reflejada en la antigüedad de parroquias y cofradías, en las fiestas sagradas, en los cultos instaurados y en la participación de muchos integrantes del clero y de órdenes religiosas en diversos sucesos que marcaron la historia caleña. No por nada entrado el siglo XIX, es recordada la clara defensa que hizo la población sobre el asunto de la expropiación franciscana, dictada como ley nacional por el presidente Tomás Cipriano de Mosquera, en $1863^{1}$, siendo figura predominante en dicha defensa, el abogado y escritor Eustaquio Palacios, quien a solicitud de la comunidad caleña elevaría una petición al Congreso de la República para que los expropiados bienes franciscanos retornaran a Cali, bajo la administración de la ciudad.

La defensa a fray Damián González, el apoyo a fray Fernando de Jesús Larrea en el siglo XVIII a la hora de crear el Colegio de Misiones de San Joaquín, la exaltación a fray Pedro de Herrera y fray José Joaquín Escobar por su participación en las gestas de Independencia son sólo algunas de las manifestaciones que exponen e ilustran el porqué la relación entre la sociedad civil y los miembros de la institución religiosa ha sido estrecha en la historia de la que antes fuera una pequeña villa.

Jesús Efrén Romero en su libro "Apuntes históricos sobre la arquidiócesis de Cali" (1973, pp. 384), expone que la erección a Diócesis, fue presentada por un grupo de sacerdotes caleños, que aprovechando la visita del Delegado Apostólico a la región, le solicitaron hiciera el pedido a la Santa Sede, para que tal idea se convirtiera en una realidad. Sin desmeritar el esfuerzo de dichos clérigos, valdría la pena señalar que tal proyecto tendría un importante acompañamiento por parte del Cabildo y de los pobladores caleños. O por lo menos así lo demuestran los documentos consultados en el que se presenta una amplia correspondencia del Cabildo y la sociedad caleña, los cuales describen el amplio interés que poseían éstos en la consecución de dicho proyecto.

En 1907, con motivo de la consagración de la basílica del Señor de Los Milagros de Buga, el delegado apostólico para Colombia, monseñor Francisco Ragonesi, realiza una visita al Valle del Cauca. Para tal efecto, las ceremonias de bendición e inauguración religiosa iniciaron el 2 de agosto de dicho año de 1907, las cuales contaron con la presencia no sólo de las autoridades civiles y eclesiásticas de la ciudad de Buga y de los padres misioneros redentoristas que se habían encargado

\footnotetext{
${ }^{1}$ Tal decreto es conocido como de "desamortización de manos muertas", medida con la que el presidente Mosquera buscaba disminuir el poder económico de la Iglesia, teniendo en cuenta que la $3^{\mathrm{a}}$ parte de las tierras cultivables le pertenecían a esta, rematándolas y redistribuyéndolas entre los nuevos compradores. La expropiación por tanto no sólo cubre a la orden franciscana sino en general a todas las comunidades religiosas presentes en el territorio nacional.
} 
de la construcción de la basílica, sino a la vez con la presencia de integrantes del Concejo y de la clerecía caleña, quienes acompañaban también al recién posesionado Arzobispo de Popayán, Monseñor Antonio Arboleda.

Con la presencia de monseñor Ragonesi, relata Jesús Efrén Romero, un grupo de padres, entre ellos: "el Presbítero Francisco A. Salazar y el Padre Uladislao González Concha, bugueños, y el Vicario Foráneo de Cali Padre Heladio Posidio Perlaza, Venían empeñados en conseguir la creación de la nueva Diócesis de Cali" (1972, p. 28).

Mientras los clérigos socializaban su deseo al delegado, sin importar la presencia del arzobispo que regentaba el devenir religioso de la región vallecaucana. El Concejo Municipal de la ciudad, preparaba la respectiva bienvenida del huésped ilustre, quien después de Buga visitaría por unos días la ciudad, específicamente la Iglesia de San Pedro y el recinto de los cabildantes.

Ante tal suceso, Ragonesi fue recibido y exaltado por los habitantes de la ciudad, quienes apelando a su devoción y cumplimiento a la institución católica y a sus representantes, asistieron, parece ser que con asiduidad, a dicho evento, más si se trataba de la visita del 'embajador' de la Santa Sede en Colombia, como muestra la presente carta remitida por el Concejo de la ciudad tanto a la Prefectura Provincial como al Ministerio de Relaciones Exteriores:

El Concejo Municipal de Cali registra complacido en el acta del presente de la visita que á esta Corporación ha hecho el Excelentísimo Señor Dn. Francisco Ragonesi, Delegado Apostólico de la Santa Sede y Decano del Cuerpo Diplomático de Bogotá, por cuanto ese honor ha sido dispensado por el ilustre Prelado como una manifestación de respeto hacia las autoridades constituidas y con cariño por el Municipio de Cali que ha hecho lo posible para que la permanencia del viajero distinguido sea grata, ligera y afectuosa, cual cumple hacerlo á un pueblo como el caleño que se precia de su amor á la Sede Romana y su adhesión al Vicario de Jesucristo en la tierra cuyo Representante en esta República es el Excelentísimo Señor Ragonesi (AHC, Fondo Concejo, 1907, fol.71).

Al parecer, la bienvenida realizada por el Concejo Municipal no sólo fue exitosa sino gratificante para el delegado quien expresaría su satisfacción, llegado a Bogotá, al presidente Rafael Reyes, pues la carta de agradecimiento referida al Concejo caleño, por parte de Miguel Cobo, integrante del ministerio de Relaciones Exteriores, exalta los honores y atenciones realizados en la ciudad. Hay que advertir que dicha visita no fue realizada sólo por Monseñor Ragonesi, pues éste contó con el acompañamiento del Arzobispo de Popayán, quien se daba a conocer a la comunidad caleña, pues ese año dicho prelado había sido preconizado en Popayán: 
Grato me es acusar recibo de su atenta nota No 319, y del acta de la sesión solemne de ese Honorable Concejo, dignamente presidido por Ud., que tuvo lugar el día once del mes de Agosto del presente año, con el fin de recibir la honrosa visita del Excmo. Señor Delegado de la Santa Sede ante el Gobierno de Colombia y el llustrísimo Señor Arzobispo de Popayán.

El Excmo. Señor Presidente de la República se encuentra muy complacido por la manera expontanea y culta, como supieron las autoridades eclesiásticas y civiles, y todos los habitantes de esta importante ciudad, corresponder á la cariñosa visita de los llustres Prelados, en su viaje por el sur de Colombia.

Por mi parte, como Miembro del Ministerio doy las gracias por su digno conducto á las honorables representantes de esa ciudad, por las atenciones que le prestaron al Ilustre Decano del Cuerpo Diplomático residente en esta capital, y envío mis sinceras felicitaciones á todos los vecinos de ese Municipio, que movidos cordialmente por el sentimiento religioso y de civismo que los distingue, se presentaron entusiastas á cumplimentar á los Eminentes Prelados, quienes no dudo, conservarán imperecedero recuerdo de tan simpática acogida (AHC, Fondo Concejo, 1907, fol.108).

Monseñor Ragonesi finalmente elevaría la petición a la Santa Sede, concurriendo con el debido proceso que se debía seguir en las aulas vaticanas. Tal proceso cursaría tres años en el Vaticano, hasta que finalmente el Papa Pío X expediría los decretos y bulas respectivas que confirmarían la erección diocesana caleña.

\section{Una Diócesis hecha realidad}

Todo parece indicar que más allá de ser ésta una iniciativa eminentemente eclesiástica, la erección a Diócesis respondía a las necesidades de un territorio que enfrentaba en los albores del siglo XX, nuevas y complejas realidades. Los motivos para erigir a Cali como Diócesis tal vez puedan entenderse con la siguiente carta enviada por un grupo de sacerdotes, al arzobispo de Popayán, monseñor Manuel Antonio Arboleda:

Los suscritos sacerdotes os manifestamos con toda la sinceridad de nuestra alma que sentimos profunda pena al desligarnos de nuestra jurisdicción con motivo de la erección de la Diócesis de Cali, a que pertenecemos.

La grande extensión del territorio, el ensanche de la población que atraiga la apertura del canal y la terminación del ferrocarril de Buenaventura son acaso los móviles que han decidido a la Santa Sede para el establecimiento del nuevo obispo. Por tres años hemos estado satisfechos de vuestra prudente administración y publicamos que nos habéis edificado altamente con vuestra virtud apostólica en este momento en que calla la voz de la adulación, os pedimos vuestra bendición. Cali, 10 de octubre de 1910.

Presbíteros: Buenaventura Jiménez, Heladio P. Perlaza, Uladislao González Concha, José Ramón Bejarano, Pedro A. Lozano, Francisco A. Salazar, Jerónimo Quintero D., José María Valdivieso, Juan de la Cruz Saavedra, Manuel A. Fernández, Bernardo Campelo, Manuel Antonio Pizarro, Cipriano 
Valencia, Luis E. Velez, Manuel J. Maza, Francisco Valverde, Vicente Sanchéz (Romero, 1972, p. 28).

Este acto de autonomía, muestra a la vez cómo el Cauca y Popayán habían perdido el protagonismo político y religioso que los había caracterizado hasta finales del siglo XIX (Valencia, 1995, p. 168). Tal separación trae consigo profundas implicaciones, entre otras económicas, puesto que con esta separación pierde el viejo departamento del Cauca las tierras más prosperas de la región.

No es casualidad que los firmantes de la carta utilizaran argumentos de índole económico, que les llevaba a proponer que con las nuevas dinámicas que vivía la región, apartada de por sí del Cauca, se hacía necesario que se instaurara un proyecto diocesano que cubriera las nuevas necesidades espirituales que en el futuro se iban a presentar. Cali, debía entonces hacerse al liderazgo de ese nuevo porvenir.

Finalmente, el Papa Pío X con el Acta Apostolicii Sedis determina la fundación de la Diócesis de Cali:
SS--- Dominos Noster Pios PP X, decreto Sacrae Congregationis Consistorialis erexit:
7 Julii 1910 - Sedem Episcopalem Caliensen (cali) provinciae ecclesiesticae Popayanensi (Popayán) in república Colombiana.
Madavit autemiden SS mos Dominos ut hac dere Litteras Apostolicae sub plumbo ad tromiten iuris expediontuv (AAS, 1910).

Sin embargo, con el decreto no concluye el proceso de erección pues faltaría aún la elección del obispo de una terna integrada por los padres Uladislao González, Heladio P. Perlaza y Francisco Salazar, y la final consagración del nuevo obispo. El nuevo obispado asumía como tarea, crear el respectivo Seminario para formación clerical, establecer procesos alrededor de la Acción católica, organizar el estado económico de la diócesis y dictar las disposiciones necesarias referentes a las visitas episcopales.

Cabe aclarar que si bien Cali ya poseía Diócesis, ésta aún seguía bajo el mandato de la Arquidiócesis de Popayán, claro que con un grado de autonomía respecto a la acción religiosa en el nuevo territorio vallecaucano. De hecho, mientras el Papa Pio X nombraba el obispo y el delegado apostólico confirmaba su presencia para la consagración, el arzobispo Mosquera fue nombrado Provisor de la Diócesis caleña.

Es con la siguiente provisión papal, que se nombra al cura caleño, Heladio Posidio Perlaza como primer obispo de la recién creada Diócesis: 
Successivis S. Congragationis Consstorialis docrets SS mus D.N. Pius P.P. X has quae seguvntur ecclesias de propio pastore providiti scihcet:

11. Agustin 1911.- Cathedrali ecclesiae Caliensi R.D. Eladium Perlaza, Vicarium Generalem in civitate vulgo Cali (AAS, 1911).

Finalmente su consagración se realiza el 24 de agosto de 1912, a la edad de 59 años. Para tal evento, el Concejo Municipal recibe una proposición para eximir del pago de impuesto por festividad a un grupo de damas caleñas, que deseaban así complementar las festividades religiosas propuestas para tal día. Por tanto, Manuel Carvajal, director de la Junta de Diócesis, realiza la correspondiente petición para que se realice exención del correspondiente impuesto:

Presidencia de la junta de la Diócesis.

Cali, enero 22 de 1912

Sr. Presidente del H. Concejo Municipal,

Presente

Con el fin de acrecer la cantidad que se necesite para la instalación de la Diócesis en esta ciudad, varias señoras y señoritas de este ciudad generosa y expotaneamente se han dirigido á la Junta que presido ofreciendo organizar una función de cuadros vivos en el Teatro Borrero.

La Junta ha aceptado el ofrecimiento de las damas, y de ahí que á nombre de ellas solicite de esa $\mathrm{H}$. Corporación la exención de los derechos fiscales para el Concierto ó Función en referencia.

Tratándose como se trata de una función para una obra que dará categoría moral y material á nuestra ciudad, no dudo que el Concejo accederá á la petición que respetuosamente se le hace.

Soy de U. muy atento Estimador, Manuel Carvajal (AHC, Fondo Concejo, 1912, fol.314).

Dicha petición es recibida finalmente por el Concejo, para ser trasladada a la comisión de Hacienda y Cuentas, encargada por demás de los gravámenes a las fiestas, juegos y funciones públicas y privadas, quien finalmente aceptaría la exención y apoyaría la festividad en torno a la conmemoración obispal.

\section{Acercamientos obispales. Recreando la vida de un obispo}

Monseñor Heladio Perlaza, nació en la ciudad de Cali, el 11 de mayo de 1853, hijo de Ángel María Perlaza y Andrea Ramírez. Estudió en el colegio de Santa Librada y luego pasó al seminario de Popayán en el año de 1873. Recibió su presbiterado en Quito el 18 de septiembre de 1880. A su regreso a Popayán, fue profesor del seminario mayor y en 1895 fue nombrado párroco de la Iglesia de San Nicolás en Cali hasta 1900, posteriormente tuvo el cargo de Vicario Foráneo hasta 1908. Es finalmente preconizado como obispo de Cali en 1911, por la provisión papal, como lo hemos reseñado. 
El prelado renuncia a su episcopado en abril de 1926 y fallece el 9 de octubre de 1937 a la edad de 84 años (Romero, 1972, pp. 23 - 34). Múltiples fueron sus obras como cabeza principal de la Diócesis caleña. El 8 de octubre del año de 1912, se abrió el seminario Mayor y las primeras ordenaciones sacerdotales las hizo Perlaza en la catedral el día 29 de junio de 1913, aunque pocos años después éste tuvo que cerrarse. Crea la parroquia de Santa Rosa en el año de 1924; en 1926 funda el semanario llamado 'La Voz Católica' que tenía como propósito divulgar la doctrina católica y dejar registro de la historia de la arquidiócesis, consigue la casa episcopal y promueve la asociación de hijos de María.

El trabajo pastoral del primer obispo si bien fue amplio, no sólo cobijó los asuntos eclesiásticos, sino que a la vez se preocupó por incentivar y motivar importantes iniciativas provenientes de la población caleña. Tal es el caso de la creación de la Asociación "Club Noel", conformado por un grupo de mujeres caleñas, que preocupadas por la salud de los niños de Cali inician toda una serie de actividades para recaudar los fondos que les permitieran fundar una institución hospitalaria para la niñez. Ante tal iniciativa, Monseñor Perlaza respalda y bendice la pronta consecución de tan noble proyecto:

Nos Heladio P. Perlaza, Obispo de Cali.

En atención a la caridad, celo y recta intención de que están animadas las dignas matronas y señoritas que integran la benéfica Asociación "Club Noel" y en consideración al piadoso fin que persiguen en pro de los niños pobres y desamparados de esta ciudad de Santiago de Cali, para la cual ponen en juego todos los medios y recursos que su inagotable caridad y ardiente celo les sugiere, venimos, haciendo uso de nuestra autoridad, y para más excitarlas hacer todo lo posible para la niñez desvalida, en aprobar, como en efecto aprobamos, la piadosa Asociación "Club Noel" así como también sus estatutos que les sirven de regla para el gobierno de la misma.

De todo corazón damos nuestra paternal bendición al "Club Noel" y a cada una de sus socias pidiendo al Divino Corazón de Jesús les conceda su gracia para proseguir labrando cada vez con más celo en obra tan loable.

Dado en Cali a petición de la Santa doña Eufemina Caicedo Roa, Presidenta del Club Noel, a 22 de Marzo de 1927.

+ HELADIO,

Obispo de Cali (Boletín Diocesano, 1944, p. 1053).

La labor del susodicho grupo de damas generó finalmente la consecución y construcción del Hospital Club Noel, institución que durante décadas ha realizado una importante labor de bienestar para con la niñez desamparada. Es además la Diócesis, la institución que brinda la venia para la consecución de tal proyecto, como parte de las dinámicas y procesos de labor social que empezaba a liderar Perlaza en su obispado. 
El Obispo Perlaza, a la vez, decide fundar un periódico que adscrito a la Diócesis, brindará a los lectores información y datos que alimentaran una verdadera educación y formación católica entre los integrantes laicos, religiosos y seglares de la diócesis. La propuesta del nuevo periódico:

... es trabajar en pro de una causa santa y a favor de la sociedad cristiana. Por tanto, No podemos mostrarnos indiferentes a las sabias enseñanzas de la Iglesia ni podemos cerrar los ojos para no admirar los hermosos frutos producidos por la labor periodística católica. De aquí el por qué hemos dispuesto que, además el periódico oficial, se edite otro en la Imprenta de la Diócesis con el título "LA VOZ CATÓLICA", que se empeñará en llevar, por todos los ámbitos de nuestra diócesis, a los hogares cristianos, las verdaderas, santas y moralizadoras enseñanzas del Evangelio, a fin de que la parte sencilla y poco instituida de nuestra santa religión, no se deje engañar y seducir por las falsas doctrinas del protestantismo y bolcheviquismo.

Esperamos confiados en que nuestros amados hijos acogerán con gusto y celo cristiano nuestra empresa y cooperarán a ella por todos los medios posibles, a fin de que nuestro esfuerzos produzcan todo el bien que deseamos para gloria Nuestro Señor y bien espiritual de la grey que nos ha sido confiado.

(L.S.) HELADIO, obispo de Cali (Boletín Diocesano, 1941, p. 376).

"La Voz Católica" difundió en un principio no sólo artículos relacionados con la religión católica y los asuntos terrenales y políticos del Vaticano, sino también noticias del contexto nacional e internacional, folletín literario, separata femenina y clasificados. Aún hoy, este periódico sigue en circulación general de tipo mensual entre las parroquias e iglesias de la ciudad.

Paralelo al periódico, el obispo Perlaza decide crear el "Boletín Diocesano", órgano de reflexión e información de la diócesis, que circuló sólo de modo interno, entre los prelados y párrocos de la jurisdicción caleña. A continuación se hace la correspondiente cita, presente en dicho Boletín, respecto a su creación:

El Excelentísimo Señor Perlaza (de santa memoria) por decreto de mayo de 1926, ordenó la publicación del Boletín y nombró director al Presbítero Doctor Mario Paz Borrero. El Excelentísimo señor Díaz, por Decreto de 12de Diciembre de 1927 dispuso el reestablecimiento del Boletín, el que continuó desde el número 4 hasta el 19. Finalmente por decreto de 25 de Enero de 1939 se ordenó el renovar dicha publicación, así el Vicario General lo ha continuado durante estos dos años sin desatender su otras obligaciones de Vicario, Capellán y Profesor del Seminario. El primer año hubo necesidad de pagar su impresión; en el año pasado, 1940, la imprenta diocesana- talleres de la Voz Católica, - se encargó de la publicación con el sólo gasto del papel (Boletín Diocesano, 1941, p. 388).

El "Boletín Diocesano" desaparecería en la década de los 50's, los números completos de éste se encuentran en el Archivo de la Arquidiócesis de Cali. En 
dicho folleto se pueden encontrar no sólo disposiciones respecto a las reglas morales que debían seguir los prelados, sino también las disposiciones tomadas por el tribunal eclesiástico respecto a divorcios y casos que atentaban contra la moral pública.

\section{En torno a la administración sacerdotal}

Respecto a la administración interna de la Diócesis, el obispo Perlaza crea toda una serie de disposiciones respecto a las prácticas y dinámicas que los párrocos y presbíteros adscritos a la dirección diocesana, debían implementar, en parte para mejorar la labor social y religiosa de los sacerdotes. Uno de esos decretos regula la organización de las fiestas religiosas, tal vez el objetivo era el de legislar las festividades que al parecer se encontraban en un estado de desorden local:

NOS, HELADIO PERLAZA,

Por la gracia de Dios y la santa sede apostólica, Obispo de Cali.

DECRETAMOS:

Ningún Sacerdote, Capellán o Rector de una Iglesia que no sea parroquial podrá publicar programas para fiestas religiosas a sus respectivas iglesias sin licencia del párroco, quien no la concederá sino de acuerdo con el Prelado.

Dado en Cali, a 17 de Julio de 1918.

+ HELADIO (Boletin Diocesano, 1941, p. 386).

Apelando a su autoridad como obispo, Perlaza exhorta entonces en sus decretos a propender por el orden y una mejor organización del trabajo de los sacerdotes locales, es por esto que indica en el siguiente decreto, que todos aquellos clérigos y padres que visitaran la ciudad, debían presentar sus correspondientes credenciales. Tal iniciativa responde, como se había mencionado anteriormente, por la necesidad del obispo de imponer nuevas dinámicas en las obligaciones espirituales de los miembros de la curia en Cali. Los documentos que a continuación se presentan, también se configuran en testigos del proceso de construcción de su autoridad como cabeza de la nueva diócesis:

NOS HELADIO P. PERLAZA

Por la gracia de Dios, y de la santa sede apostólica, Obispo de Cali

Considerando:

Que es obligación de conciencia para los católicos asistir al santo sacrificio de la misa los domingos y días festivos.

Que la iglesia a fin de que los fieles cumplan con este precepto, se le concede la facultad de binar, y excita a los obispos a que procuren que los sacerdotes celebren el santo sacrificio los días festivos;

Que es deber de los Obispos facilitar el cumplimiento de los deberes religiosos.

DECRETAMOS: 
1- Todo sacerdote que llegue a nuestra ciudad capital, no podrá celebrar en ninguna de nuestras iglesias la santa misa, si primero no comunica nuestra curia por sí o por otro, su llegada y el tiempo que desea permanecer; y si fuere, extraordinario debe presentar sus comendaticias mensuales.

2- El sacerdote que amanezca en nuestra ciudad capital el sábado o víspera de fiesta, no podrá separase de ella, aún cuando sea para ejercer su ministerio en otra parroquia si fuere diocesano, sin haber pedido antes licencia al prelado. El sacerdote que faltare a este mandato quedará ipso facto privado de las facultades ministeriales.

3- Toca al ordinario distribuir los domingos y días festivos las misas de los sacerdotes que estén en la ciudad capital y no beneficio en ella.

Dado en Cali, a 15 de noviembre de 1925

HELADIO P. PERLAZA, obispo de Cali (Boletin Diocesano, 1940, p. 73).

Continuando con la idea del orden en la diócesis, Perlaza, preocupado por el estado educativo y religioso de los integrantes diocesanos, instaura una cátedra de moral, para así evitar el 'relajamiento de la instrucción', del clero respecto a lo religioso, lo teológico y lo dogmático:

1- CONFERENCIAS MENSUALES- El Excmo. Sr. Perlaza, por decreto de 1920 quiso dar cumplimiento a lo estatuído por el canon 131, pero sólo en el mes de Abril de 1939 se iniciaron los casos de moral hasta conseguir hay la marcha regular en todas las Vicarías de las conferencias mensuales. No se oculta que estos estudios influyen considerablemente en la mejor instrucción del clero en las ciencias sagradas de la moral, del derecho y de la Liturgia (Boletín Diocesano, 1941, p. 338).

La erección a diócesis requería de una persona capaz no sólo de desligarse de la protección y autoridad de Popayán, sino también de imponer un nuevo estado de prácticas religiosas que permitieran a la diócesis caleña sobresalir y demostrar el porqué era necesario adquirir la autonomía. Se podría pensar que con la lejanía del poder payanés, las circunstancias de relajación religiosa en el territorio vallecaucano eran más comunes de lo que se pensaba, por eso los decretos del obispo intentaban mejorar tal situación e imponer nuevos procesos religiosos en la nueva diócesis.

\section{Epílogo}

Resulta claro que la religión representa un campo de acción simbólico, social y cultural con gran importancia e influencia en las sociedades humanas. Por siglos, la religión católica ha construido fuertes procesos de socialización en torno a sus feligreses y a las prácticas devocionales que incorpora. Por tanto, el estudio tanto de su estructura eclesiástica como institución, así como de dichas prácticas y dinámicas que se perpetúan y mutan temporal y espacialmente, se convierten en importantes objetos de estudio, trabajo y reflexión. 
Para el caso específico del presente artículo, es determinante afirmar que el proceso de constitución de Cali como Diócesis y posterior Arquidiócesis, se configuran como sucesos importantes para el devenir religioso de un territorio que no gozaba de autonomía eclesiástica. Tal independencia permitió originar procesos eclesiales de envergadura como la creación de instituciones educativas, centros comunitarios, parroquias y en general, espacios en donde por casi cien años los fieles caleños, y en general vallecaucanos, han vivificado su fe y devoción católica.

Es importante afirmar que el devenir histórico de la Diócesis y Arquidiócesis de Cali, estuvo incluso ligado a los procesos políticos, sociales, culturales y económicos del departamento del Valle del Cauca, pues la Iglesia caleña se ha constituido a través del tiempo, en importante institución de acompañamiento, diálogo y ayuda a las instituciones públicas y privadas que han liderado el desarrollo en nuestro departamento.

La reflexión histórica que aquí se presenta, es por tanto inacabada, pues aún la Arquidiócesis de Cali con todas sus sedes sufragáneas siguen dinamizando y liderando procesos religiosos y de renovación social. La puerta está abierta entonces a los investigadores históricos para que estudien tales dinámicas.

\section{Bibliografía}

\section{Fuentes documentales}

'Proposiciones'. Archivo Histórico de Cali. Fondo Concejo. Tomo 1, 1907. fol 71.

'Correspondencia'. Archivo Histórico de Cali. Fondo Concejo. Tomo 1. 8 de octubre de 1907. fol 108.

"Correspondencia". Archivo Histórico de Cali. Fondo Concejo. Tomo II. Enero 22 de 1912. Fol 314.

'Commentarium officiale'. En Acta Apostoliciae Sedis. Ciudad del Vaticano, Annus II, Vol II, Iulii 1910. № 13.

"Sacra Congregatio Consistoriaus. Proviso Ecclesiarum". En Acta Apostoliciae Sedis. Ciudad del Vaticano, Annus III, Vol II, Agustin 1911. Archivo de la Arquidiócesis de Cali.

"Decreto". En Boletín Diocesano, № 24. Cali, mayo de 1940. P. 73. Archivo de la Arquidiócesis de Cali.

"Realizaciones". En Boletín Diocesano, N44. Cali, enero de 1941. P. 338. Archivo de la Arquidiócesis de Cali. 
"Curia administrativa. Decreto 253". En Boletín Diocesano, № 47. Imprenta Diocesana. Cali, abril de 1941. p. 386. Archivo de la Arquidiócesis de Cali.“

"La carta del Obispo". En Boletín Diocesano, N 83 y 84 . Cali, abril y mayo de 1944. Imprenta Departamental. p. 1053.

\section{Fuentes bibliográficas}

Romero, Jesús Efren. Apuntes históricos sobre la arquidiócesis de Cali. Imprenta Departamental. Cali: 1973.

Valencia Llano, Alonso. En: Historia del Gran Cauca. Universidad del Valle. Cali: 1995.

Recibido: 1 de marzo de 2010.

Aprobado: 11 de mayo de 2010. 